\title{
Tissue Matrices Scaffold for the Preparation of Lithium Cobalt Oxide
}

\author{
Parbhej Ahamed, Mohammad Abu Yousuf* \\ Department of Chemistry, Khulna University of Engineering \& Technology, Khulna, Bangladesh \\ Email: *yousuf@chem.kuet.ac.bd
}

How to cite this paper: Ahamed, P. and Yousuf, M.A. (2020) Tissue Matrices Scaffold for the Preparation of Lithium Cobalt Oxide. Advances in Materials Physics and Chemistry, 10, 111-124.

https://doi.org/10.4236/ampc.2020.105009

Received: May 5, 2020

Accepted: May 25, 2020

Published: May 28, 2020

Copyright $\odot 2020$ by author(s) and Scientific Research Publishing Inc. This work is licensed under the Creative Commons Attribution International License (CC BY 4.0).

http://creativecommons.org/licenses/by/4.0/

\begin{abstract}
This study reports an innovative approach of solid state reaction for the production of lithium cobalt oxide $\left(\mathrm{LiCoO}_{2} / \mathrm{LCO}\right)$ using commercially available tissue matrices. $\mathrm{Li}^{+}$and $\mathrm{Co}^{2+}$ grafted tissue matrices calcined at $700^{\circ} \mathrm{C}$ for 6 hours to prepare black color LCO materials. A series of techniques such as FT-IR, XRD, FESEM, TGA and UV-visible spectroscopy were applied for characterization of the prepared LCO materials. Fourier-transform infrared spectroscopy (FT-IR) data identified the vibration mode of $\mathrm{CoO}_{6}$ and O-Co-O in the prepared LCO materials. FESEM images of tissue assisted LCO possessed larger size and voids compared to the LCO prepared without any tissue matrix. X-ray diffraction (XRD) data approved the layer structure of LCO with $\mathrm{R} 3 \mathrm{~m}$ space group. Analysis of XRD spectra revealed that tissue matrices reduced the unit cell lattice constant of LCO materials. Properties such as X-ray density $\left(\rho_{\mathrm{x}}\right)$, bulk density $\left(\rho_{\mathrm{b}}\right)$ and grain size $(D)$ have been calculated from the XRD spectrum for assessment of the structural properties of the prepared LCO materials. Thermal analysis results indicated the relation of tissue matrix combustion carbon coating on LCO surface for different absorption behavior of the prepared materials. The band gap of tissue assisted LCO was found to decrease compared to the LCO prepared without tissue matrix. The synthesis method used in this study can be broadly applicable as a simple and inexpensive approach for the preparation of LCO materials of Li-ion battery.
\end{abstract}

\section{Keywords}

Lithium Cobalt Oxide, Tissue Matrix, Absorption, Solid State Reaction

\section{Introduction}

Lithium cobalt oxide as an active cathode material has been playing a major role 
for today's commercial lithium ion battery since its first market introduction by Sony group, Japan, in 1991 [1] [2] [3] [4] [5]. Portable electronics and electric vehicles perpetual demand around the globe has made LCO a focal point of ongoing LIB research. Statistically more than $31 \%$ commercially manufactured LIB use LCO because of its well-ordered layer structure for fast and reversible lithium intercalation [5] [6]. Ideally, layered crystal structure LCO is considered an important material for energy storage solution because of its high specific energy density and volumetric energy density. However, until now the discharge capacity $(140 \mathrm{mAh} / \mathrm{g})$ of this key materials is over half of its theoretical capacity (274 mAh/g) [7] [8]. Such behavior of capacity loss belonged to the irreversible phase change of LCO during de-intercalation and/or intercalation process [9] [10] [11]. It has been reported that phase changes of LCO is a function of the extraction of $\mathrm{Li}^{+}$ions from LCO and its operating potential [12]-[17]. This structural phase transitions of LCO represented a dramatic change in the mechanical properties of the LCO crystallite [18].

To solve the aforementioned dilemma of LCO, various methods such as solid state reaction [19] [20], sol-gel [21] [22], hydrothermal [23], co-precipitation [24], pulsed layer deposition [25], freeze-drying rotary evaporation [26] have been developed to maintain its structure stability. These methods require long reaction time, complex conditions, chemicals, large quantity of solvents and organic materials, thus affect the environment negatively. In addition, they are still far way to prepare stable structure LCO because of their strict synthetic conditions and complicated procedures [27]. Regarding this context the development of an eco-friendly method for the fabrication of LCO will be worthy.

This study demonstrated a novel green synthesis approach of tissue matrix and water to prepare LCO materials. The purpose of using tissue was to provide a soft template for the insertion of metal components into its pore through physical interaction. It is found that the ordered cross-linked tissue scaffold could be a useful means of preparing nanostructured LCO without any special conditions such as expensive equipment, large quantity of solvents, organic materials and others. To the best of our knowledge, research regarding the use of tissue scaffold for optimizing the structure of LCO materials has not yet been published elsewhere. So, the formation of LCO materials from the metals ions captured tissue scaffold and analysis of the prepared materials structure using various techniques have been presented in this study.

\section{Experimental}

$\mathrm{LiOH} \cdot \mathrm{H}_{2} \mathrm{O}$ (Loba Chemie Co. Ltd., India), $\mathrm{CoSO}_{4} \cdot 7 \mathrm{H}_{2} \mathrm{O}$ (Merck, Germany), wet tissue (Baby wipes, Pozzy, Istanbul, Turkey) and facial tissue (Fresh, Bangladesh) were purchased and used as received. Stoichiometric amount of $\mathrm{LiOH} \cdot \mathrm{H}_{2} \mathrm{O}$ was dissolved in deionized water. Then the solution was absorbed by tissue. $\mathrm{LiOH} \cdot \mathrm{H}_{2} \mathrm{O}$ aqueous solution absorbed tissue was then evaporated at $110^{\circ} \mathrm{C}$ to remove water. In the same way $\mathrm{LiOH} \cdot \mathrm{H}_{2} \mathrm{O}$ grafted tissue was placed into Co- 
$\mathrm{SO}_{4} \cdot 7 \mathrm{H}_{2} \mathrm{O}$ solution. After complete absorption of $\mathrm{CoSO}_{4} \cdot 7 \mathrm{H}_{2} \mathrm{O}$ aqueous solution the tissue matrices were evaporated again at $110^{\circ} \mathrm{C}$ to eliminate water. Both $\mathrm{LiOH} \cdot \mathrm{H}_{2} \mathrm{O}$ and $\mathrm{CoSO}_{4} \cdot 7 \mathrm{H}_{2} \mathrm{O}$ grafted tissue matrices were then placed into a muffle furnace and calcined at $700^{\circ} \mathrm{C}$ for 6 hours. The prepared sample was cooled down to room temperature and taken into a vial. The aforementioned procedure was followed to prepare LCO using two types of tissue paper separately. Prepared samples were subjected to FT-IR, XRD, FESEM, TGA and UV-visible spectroscopy techniques for characterization.

\subsection{Fourier Transform Infrared Spectroscopy (FT-IR)}

Samples for FT-IR measurements were made by mixing LCO materials in $\mathrm{KBr}$ pellets. FT-IR spectra were recorded using IR Tracer-100 of Shimadzu Corporation, Japan. The prepared LCO samples were finely grinded with $\mathrm{KBr}$. The mixture was then pressed with a pressing machine to obtain a transparent pellet. Pellet for each material was scanned in the wave number range of $400-4000$ $\mathrm{cm}^{-1}$.

\subsection{Powder X-Ray Diffraction (XRD)}

The phases present in the prepared LCO materials was confirmed with a high resolution Bruker Advance D8 XRD diffractometer. The diffractometer was

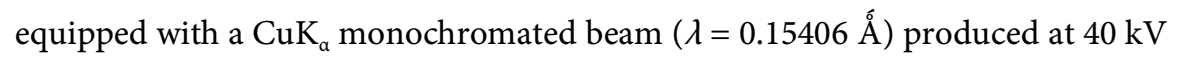
and $40 \mathrm{~mA}$. The sample holders have been loaded by simply pouring it with LCO materials. Then it was mounted on the diffractometer. The scanning $(2 \theta)$ was performed from $10^{\circ}$ to $70^{\circ}$.

\subsection{Parameters Such as X-Ray Density, Bulk Density and Grain Size Determination}

Various structural information such as X-ray density $\left(\rho_{x}\right)$, bulk density $\left(\rho_{b}\right)$, grain size $(D)$ and percentage of porosity of the prepared samples were calculated from the obtained XRD spectra using the following equations.

$$
\text { X-ray density, } \rho_{x}=\frac{Z M}{N V}
$$

where $M$ is the molecular weight of the corresponding composition, $N$ is the Avogadro's number $\left(6.023 \times 10^{23} \mathrm{~mole}^{-1}\right), V$ is the volume of the unit cell and $Z$ is the number of molecules per unit cell.

$$
\text { Bulk density, } \rho_{b}=\frac{m}{V}
$$

where $m$ is the mass and $V$ is the volume of the sample.

$$
\text { Grain size, } D=\frac{0.9 \lambda}{\beta \cos \theta}
$$

where $D$ is the crystal size; $\lambda$ is the wavelength of the $\mathrm{X}$-ray radiation $(\lambda=$ $0.15406 \mathrm{~nm}$ ) for $\mathrm{CuK}_{\alpha}$ and $\beta$ is the line width at half-maximum height. 


\subsection{Field Emission Scanning Electron Microscopy (FESEM)}

The morphologies of the prepared LCO materials were investigated using JSM-7610, Shimadzu Corporation, Japan. Sample was suspended in ethanol. Then a conductive carbon tape was pasted on the alumina plate. 2 - 3 drops of the suspended sample was put on the conductive carbon tape. It was thereafter allowed to dry for a sufficient period of time. Excess powder on the sample plate was removed using an air blower and sputtered with gold. Finally, the sample plate was mounted on the sample chamber for SEM operation.

\subsection{Thermogravimetric Analysis (TGA)}

Thermogravimetric analyses (TGA) of the prepared LCO materials were performed using STA7200, Hitachi thermal analysis system. LCO material was added to a TGA sample holder pan. Mass of the sample was noticed with a precision balance. It was therefore held on the pan at room temperature under a flow of nitrogen gas to create inert environment for the sample and gases such as oxygen, water vapor were driven off. Sample was then heated at a rate of $10^{\circ} \mathrm{C} /$ min until the temperature reached from room temperature to $550^{\circ} \mathrm{C}$. TGA curves of the samples were obtained from computer based TGA program.

\subsection{UV-Visible Spectroscopy}

Band gap energy for each LCO material was determined by using the respective absorption spectrum obtained using UV-1800 spectrophotometer of Shimadzu Corporation, Japan, in the range $200-800 \mathrm{~nm}$. LCO sample was suspended in ethanol by shaking well. Then it was taken in a cuvette and was placed into the cuvette holder of UV-visible spectrometer for measuring the absorbance spectrum.

\section{Results and Discussion}

Figure 1 is a schematic illustration of the process used to prepare tissue assisted LCO materials. The tissue matrix comprised of cellulose backbone material absorbed $\mathrm{Li}^{+}$ions from its aqueous solution. Upon evaporation $\mathrm{Li}^{+}$ions were grafted into the pores of cellulose backbone by cross-linking with cellulosic hydroxyl groups. Then, $\mathrm{Co}^{2+}$ ions were inserted into $\mathrm{Li}^{+}$grafted tissue matrix in the same way. Calcination reaction at $700^{\circ} \mathrm{C}$ removed tissue templates and yielded LCO materials. LCO without tissue template was also prepared under the same reaction condition. The prepared samples were characterized using FT-IR, XRD, FESEM, TGA and UV-visible spectroscopy techniques.

FT-IR spectrum of LCO samples recorded within $400-4000 \mathrm{~cm}^{-1}$ and presented in Figure 2. The oxide network of LCO is mainly composed of stretching mode of Co-O bond and bending mode of $\mathrm{O}-\mathrm{Co}-\mathrm{O}$ bond in the octahedral $\mathrm{CoO}_{6}$ moiety [28] [29] [30] [31] [32] as a high frequency shoulder. According to Huang and Frech IR active mode of $\mathrm{LiO}_{6}$ octahedral moiety appears as a lower frequency shoulder due to the motion of lithium atom [33]. FT-IR analyses exhibit that the 

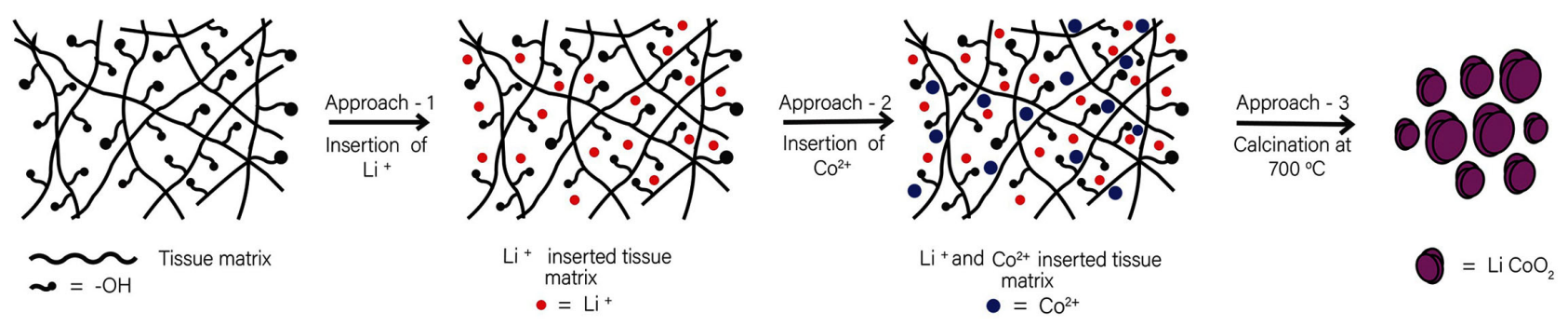

$=\mathrm{LiCoO}_{2}$

Figure 1. Schematic diagram of the preparation of tissue assisted LCO materials.

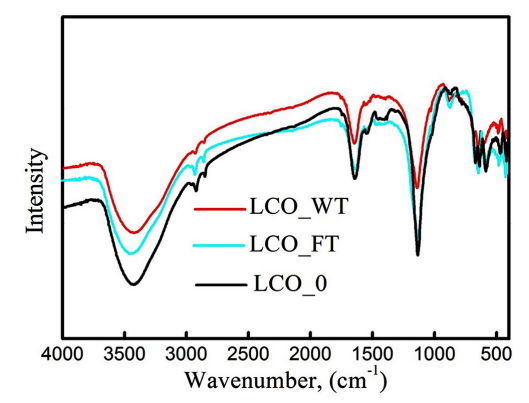

Figure 2. FTIR spectrum of the prepared LCO materials.

position of $v\left(\mathrm{CoO}_{6}\right)$ and $\delta(\mathrm{O}-\mathrm{Co}-\mathrm{O})$ vibration mode located between 570 - 650 $\mathrm{cm}^{-1}$ and $470 \mathrm{~cm}^{-1}$, respectively. Thus, possible stretching vibration of Co-O and bending motion $\mathrm{O}-\mathrm{Co}-\mathrm{O}$ of $\mathrm{CoO}_{6}$ octahedron of prepared $\mathrm{LCO}$ materials recorded by FT-IR spectroscopy. Location of peak positions in these regions are also closely resembled with the reported values found in the literature [34]. The absorption spectrum of $\mathrm{LiO}_{6}$ octahedron below $300 \mathrm{~cm}^{-1}$ has not been recorded due to instrument limitation. Thus, the appearance of distinct peaks in the region of $400-600 \mathrm{~cm}^{-1}$ confirmed the formation of LCO with R3m space group.

Appearance of peak for $\mathrm{C}=\mathrm{O}$ vibration observed in the region of $1140-1150$ $\mathrm{cm}^{-1}$. The absorption at 1636 and $3400 \mathrm{~cm}^{-1}$ have been identified for the bending and stretching vibration modes of $-\mathrm{OH}$ group of absorbed water molecules on the surface of the $\mathrm{LCO}$ [35]. Peaks related to $\mathrm{C}=\mathrm{O}$ and $-\mathrm{OH}$ groups has been ascribed for the absorption of $\mathrm{CO}_{2}$ and water on LCO in the air. These results are in close agreement with other studies [36] and suggested the disordered rhombohedral LCO structure as evidenced by the presence of small band at $\approx 450 \mathrm{~cm}^{-1}$ [29].

The XRD patterns of the prepared LCO compounds are given in Figure 3. The reflection lines located at $2 \theta$ of $18.977,36.821,38.519,44.771,49.037$, $59.294,65.186$ and 68.573 corresponding to the planes (003), (101), (006)/(012), (104), (015), (107)/(009), (018)/(110) and (113) agree well with the standard XRD patterns of LCO [37]. From the XRD pattern it is seen that crystalline LCO formed along with some impurity phases. The possible impurities are $\mathrm{Li}_{2} \mathrm{CO}_{3}$ [38] and $\mathrm{Co}_{3} \mathrm{O}_{4}$ [39]. Impurities formation may have been resulted from the non-homogeneous distribution of metal ions $\left(\mathrm{Li}^{+}\right.$and $\left.\mathrm{Co}^{2+}\right)$ into the tissue matrix. However, the layered structure of the LCO materials is marked by the presence of (003) and (104) peak [40]. The clear splitting of (006)/(012) and (108)/(110) 
peaks are also confirmed about LCO layered structure [41]. XRD information of the prepared LCO materials is summarized in Table 1.

In the layer structure $\mathrm{LCO}$ crystallizes where $\mathrm{Li}^{+}$ions present as edge sharing octahedra between the extended anionic sheets of cobalt and oxygen atoms. Each close packed layer arranged is firmed by piling the atoms in a regular triangular lattice. According to Bragg's law [42],

$$
2 d \sin \theta=n \lambda
$$

where $n$ is the order of diffraction (usually $n=1$ ), $\lambda$ is the X-ray wavelength and $d$ is the spacing between planes of given Miller indices $h, k$ and $l$. Interplanar spacing $d$ of a hexagonal rhombohedral structure is related to the lattice constants a, $\mathrm{c}$ and the Miller indices by the following relation [42].

$$
\frac{1}{d_{h k l}^{2}}=\frac{4}{3}\left(\frac{h^{2}+h k+k^{2}}{a^{2}}\right)+\frac{l^{2}}{c^{2}}
$$

The lattice constant $a, c$ were calculated from the splitting peaks (107) and (009) of XRD spectrum using Equation (5). Values of $a$ and $c$ are almost consistent with those reported by Akimoto et al. [43]. The lattice parameter values of the tissue assisted LCO are little bit smaller than the LCO prepared without using tissue. This small decrease of the lattice parameter value of the tissue assisted LCO may be related to a higher electronic attraction between the $\mathrm{CoO}_{2}$ layers. The obtained lattice parameter values of the prepared LCO materials were used to calculate unit cell volume using the following formula [44].

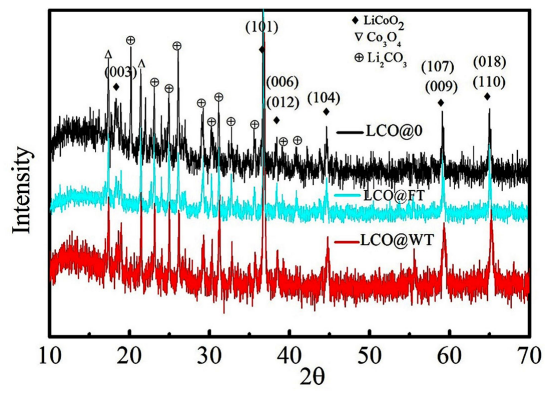

Figure 3. XRD spectra of the prepared LCO materials.

Table 1. Positions of the X-ray peaks, interplanar spacing and corresponding miller in-

\begin{tabular}{|c|c|c|c|c|c|c|c|}
\hline & $2 \theta$ & 18.34 & 36.68 & 38.48 & 44.80 & 59.28 & 65.18 \\
\hline \multirow[t]{3}{*}{ LCO_0 } & $d(\AA)$ & 4.8335 & 2.4480 & 2.3376 & 2.0214 & 1.5573 & 1.4299 \\
\hline & (hkl) & (003) & (101) & $(006) /(012)$ & (104) & $(107) /(009)$ & $(018) /(110)$ \\
\hline & $2 \theta$ & 18.93 & 36.80 & 38.51 & 44.70 & 59.32 & 65.19 \\
\hline \multirow[t]{3}{*}{ LCO_FT } & $d(\AA ̊)$ & 4.6821 & 2.4401 & 2.3357 & 2.0257 & 1.5565 & 1.4297 \\
\hline & (hkl) & (003) & (101) & $(006) /(012)$ & (104) & $(107) /(009)$ & $(018) /(110)$ \\
\hline & $2 \theta$ & 18.97 & 36.81 & 38.49 & 44.77 & 59.30 & 65.18 \\
\hline \multirow[t]{2}{*}{ LCO_WT } & $d(\AA)$ & 4.6744 & 2.4394 & 2.3370 & 2.0224 & 1.5570 & 1.4299 \\
\hline & (hkl) & (003) & (101) & $(006) /(012)$ & (104) & $(107) /(009)$ & $(018) /(110)$ \\
\hline
\end{tabular}
dices of each plane. 


$$
V=\frac{2}{\sqrt{3}} a^{2} c
$$

Grain sizes of LCO samples were calculated using Equation (3). The calculated values are given in Table 2 . The comparison of lattice parameter and volume of the prepared LCO samples with their grain size are depicted in Figure 4. It is evident from Figure 4 that the tissue assisted LCO grain sizes are larger relative to the LCO_0 one. This is possibly associated with the grain growth environment of LCO precursors. In case of LCO_0 the precursors have larger dispersion and the grain growth may be occurred in a more disordered way. In contrast, the dispersion of LCO precursors in tissue matrices is occurred in the ordered cellulose network of tissue matrix. The ordered cellulose network and its combustion energy may favor the formation of larger grain sizes LCO.

X-ray density $\left(\rho_{x}\right)$ and bulk density $\left(\rho_{b}\right)$ of the prepared LCO materials has been calculated using Equations (1) and (2), respectively. These values are listed in Table 3. X-ray density $\rho_{x}$ was found to be slightly increased for tissue matrix assisted LCO materials. This may be related to LCO crystallite growth process in presence of tissue matrix. Combustion of tissue matrix might enhance LCO precursor's nucleation rate and produced dense LCO particles. Therefore, the electronic attraction between the $\mathrm{CoO}_{2}$ layers of LCO crystal structure has been increased. It is found that the bulk density slightly decreased with using tissue matrix. This may be due to the formation of voids on the surface of LCO particles. The relation between X-ray density and bulk density is depicted in Figure 5.
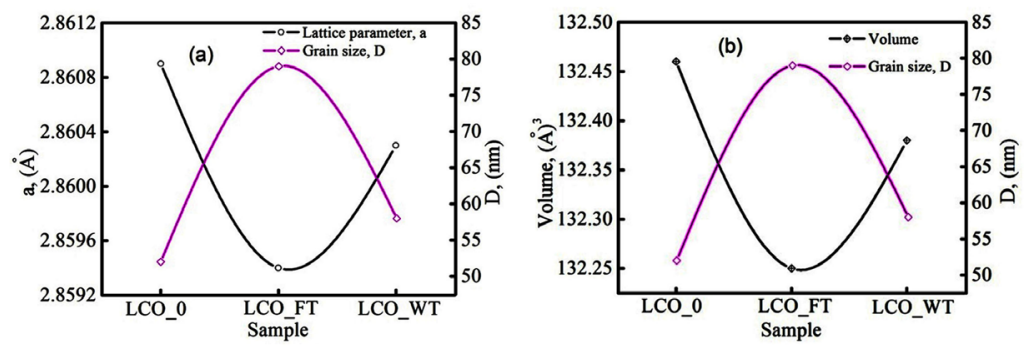

Figure 4. Comparison of (a) lattice parameter with grain size (b) volume with grain size.

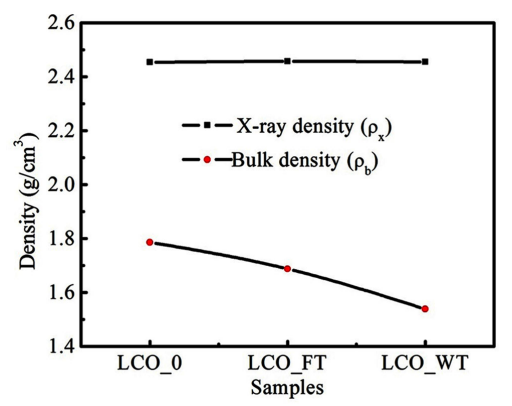

Figure 5. Variation of bulk density and X-ray density of the prepared LCO in cellulose matrix. 
Table 2. Structural information of the prepared LCO materials.

\begin{tabular}{|c|c|c|c|c|c|}
\hline Sample & $a(\AA ̊)$ & $c(\AA ̊)$ & $\mathrm{c} / \mathrm{a}$ & $V(\AA)^{3}$ & Grain sizes (nm) \\
\hline LCO_0 & 2.8609 & 14.0157 & 4.8990 & 132.46 & 52 \\
\hline LCO_FT & 2.8594 & 14.0085 & 4.8991 & 132.25 & 79 \\
\hline LCO_WT & 2.8603 & 14.0130 & 4.8991 & 132.38 & 58 \\
\hline
\end{tabular}

Table 3. X-ray density, bulk density and porosity of the prepared samples.

\begin{tabular}{ccc}
\hline Sample & X-ray density, $\rho_{x}\left(\mathrm{~g} / \mathrm{cm}^{3}\right)$ & Bulk density, $\rho_{b}\left(\mathrm{~g} / \mathrm{cm}^{3}\right)$ \\
\hline LCO_0 & 2.4534 & 1.7865 \\
LCO_FT & 2.4573 & 1.6881 \\
LCO_WT & 2.4549 & 1.5389 \\
\hline
\end{tabular}

Field emission scanning electron micrographs are shown in Figure 6. It represents the distinctly different morphologies of the prepared LCO samples. Tissue assisted LCO samples consist of agglomerated particles whereas LCO_0 do not. The prepared LCO are mainly rhombohedral in shape [36]. The variation in the size of the particles clearly reveals that tissue matrix greatly affect the morphology of the prepared LCO material. LCO_0 represents smaller particle size compared to LCO produced in presence of tissue matrices. This may be related to the crystallite growth environment. During the formation of LCO_A and LCO_AL the crystallite growth environment got more energy from the combustion of tissue matrix and resulted larger size particles compared to LCO_0. The respective crystallite sizes (Table 2) of LCO materials as calculated from the $\mathrm{XRD}$ spectra are in good agreement with this observation.

Thermal analyses of the prepared LCO samples were performed in the temperature range of $30^{\circ} \mathrm{C}$ to $550^{\circ} \mathrm{C}$. Figure 7 shows the TGA plot of LCO samples.

The initial weight loss below $300^{\circ} \mathrm{C}$ is related to the losses of absorbed water molecules on LCO samples [45]. Weight loss for both tissues assisted LCO is about $3 \%$ while that for LCO_0 is $4.2 \%$. The attachment of carbon on LCO from tissue matrix during calcination may play an important role to inhibit the absorption of water molecule. As a result, weight loss by tissue matrix assisted LCO is less than LCO_0. The recorded thermogram remains almost same at temperature $>320^{\circ} \mathrm{C}$. It followed a plateau up to $550^{\circ} \mathrm{C}$ which implies the formation of high temperature R3m LCO phases [45].

According to valence bond theory, $\mathrm{LiCoO}_{2}$ is formed through the hybridization of $\mathrm{O} 2 \mathrm{p}$ orbital with Co $3 \mathrm{~d}$ orbital [46]. Some spectroscopic measurements such as X-ray photoelectron spectroscopy (XPS) and X-ray absorption spectroscopy (XAS) suggested that $\mathrm{O} 2 \mathrm{p}-\mathrm{Co} 3 \mathrm{~d}$ hybridized orbital in $\mathrm{LiCoO}_{2}$ present as $\left(t_{2 g}\right)^{6}-\left(e_{g}\right)^{0}$ [47] [48]. The electronic transition in $\mathrm{LiCoO}_{2}$ takes place as a result of d-d transition of electron from $\left(t_{2 g}\right)^{6}$ orbital to $\left(e_{g}\right)^{0}$ orbital [49] [50]. The investigated optical absorption spectra of the prepared LCO materials in ethanol are shown in Figure 8. 
The transition of electron is broadened and appeared after $300 \mathrm{~nm}$. This broadening and shifting of absorption band to lower wavelengths (higher energies) may be due to the favorable interaction of $\mathrm{Co}^{3+}$ with protic ethanol solvent. The absorption peak for LCO_0 is located at $277 \mathrm{~nm}$. Tissue matrix assisted LCO_FT and LCO_WT located at $279 \mathrm{~nm}$ and $281 \mathrm{~nm}$, respectively. Two reasons are expected for the variation of absorption peaks position of the prepared LCO materials. One is related to the size of the particles. The other is the coating of carbon on LCO from the combustion of tissue matrices. However, the measured absorption spectra are typical of $\mathrm{LiCoO}_{2}$ as reported by Ghosh et al. [36].

The band gap values of LCO samples were determined by using their respective absorption spectra through Tauc formula [51].

$$
(\alpha h v)^{1 / n}=A\left(E-E_{g}\right)
$$

where $\alpha$ is the absorbance coefficient, $A$ is a constant, $E=h v$ is the photon energy, $E_{g}$ is the band gap energy and $n=1 / 2$ for direct transition of electron. The $E_{g}$ values of LCO samples are obtained by extrapolating the linear portions of $(\alpha h v)^{2} v s h v$ graph to intercept the photon energy axis. Tauc plots of LCO samples are given in the inset of Figures 8(a)-(c). $E_{g}$ values of LCO_0, LCO_FT and LCO_WT are 5.4577, 5.4361 and $5.4285 \mathrm{eV}$, respectively. The calculated band gap energies are related to their respective particle size (Table 2) and coated carbon on LCO surface. $E_{g}$ values variation of LCO is represented in the following Figure 9. It is seen that $E_{g}$ values of LCO_FT and LCO_WT samples are reduced by $0.4 \%$ and $0.5 \%$ in compared to LCO_0 sample.

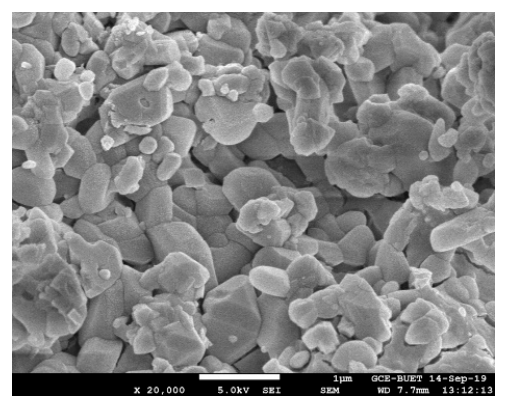

(a)

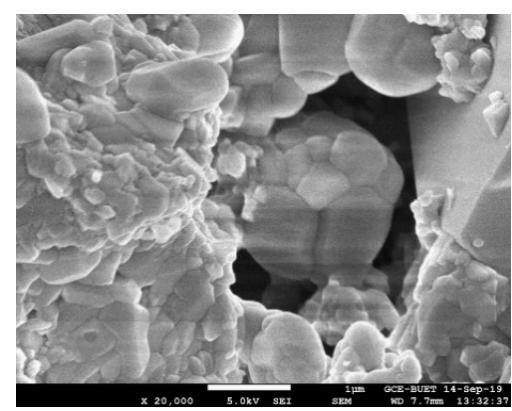

(b)

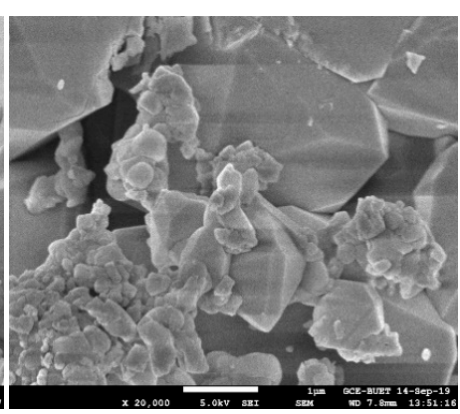

(c)

Figure 6. FESEM images of $\mathrm{LiCoO}_{2}$ (a) without tissue (b) using facial tissue (c) using wet tissue. 


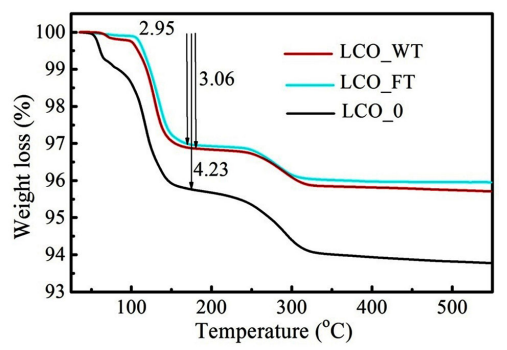

Figure 7. Thermal analysis of the prepared LCO materials.
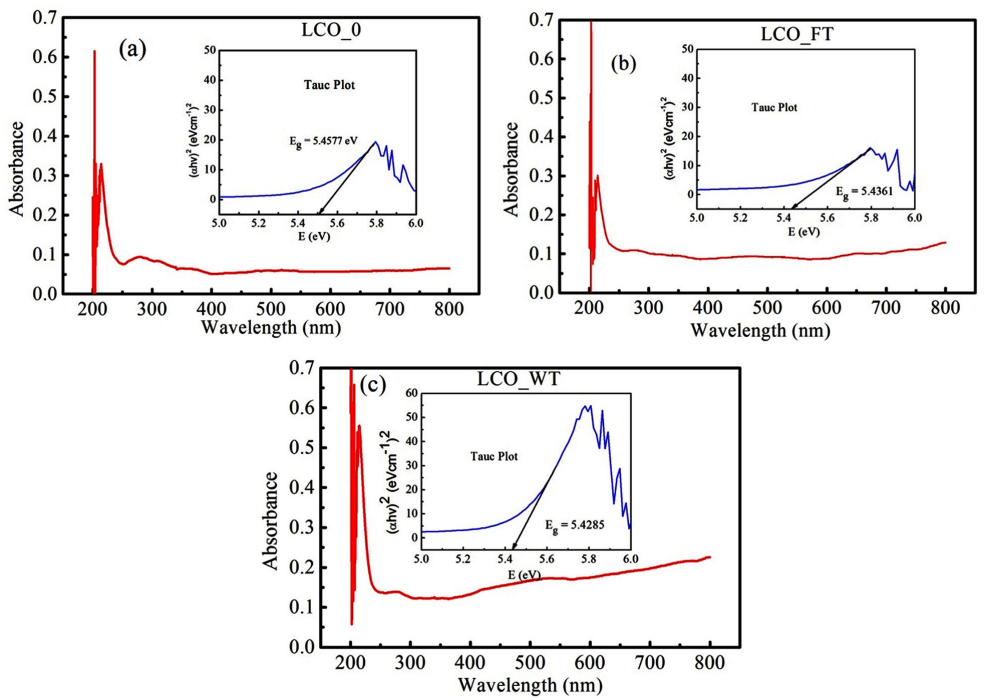

Figure 8. UV-visible spectrum of the prepared LCO materials.

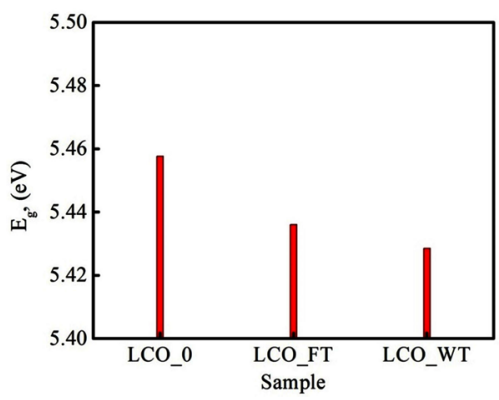

Figure 9. Variation of band gap energy of LCO samples.

\section{Conclusion}

Tissue matrix as a soft scaffold allowed the formation of LCO with some by products $\mathrm{Li}_{2} \mathrm{CO}_{3}$ and $\mathrm{Co}_{3} \mathrm{O}_{4}$. FT-IR identified the presence of $\mathrm{CoO}_{6}$ vibration peak in the prepared LCO materials. XRD studies confirmed the layer structure in LCO phase with R3m space group. Lattice parameter of tissue matrix assisted LCO decreased slightly compared to LCO_0. Grain sizes of tissue assisted LCO are larger compared to LCO_0 one. It is evidenced by both XRD and FESEM. Thermogravimetric analysis showed that tissue assisted LCO absorbs less 
amount of water. The narrowing of band gap value of tissue assisted LCO evidenced the coating of carbon on LCO surface.

\section{Acknowledgements}

The Authors gratefully acknowledge the support from the Khulna University of Engineering \& Technology, Bangladesh in doing the research.

\section{Conflicts of Interest}

The authors declare that they have no conflict of interests.

\section{References}

[1] Li, X., Yang, Z., Fu, Y., Qiao, L., Li, D., Yue, H. and He, D. (2015) Germanium Anode with Excellent Lithium Storage Performance in a Germanium/Lithium-Cobalt Oxide Lithium-Ion Battery. ACS Nano, 9, 1858-1867. https://doi.org/10.1021/nn506760p

[2] Zubi, G., Dufo-López, R., Carvalho, M. and Pasaoglu, G. (2018) The Lithium-Ion Battery: State of the Art and Future Perspectives. Renewable and Sustainable Energy Reviews, 89, 292-308. https://doi.org/10.1016/j.rser.2018.03.002

[3] Yoshino, A. (2012) The Birth of the Lithium-Ion Battery. Angewandte Chemie International Edition, 51, 5798-5800. https://doi.org/10.1002/anie.201105006

[4] Whittingham, M.S. (2004) Lithium Batteries and Cathode Materials. Chemical Reviews, 104, 4271-4302. https://doi.org/10.1021/cr020731c

[5] Goodenough, J.B. and Kim, Y. (2010) Challenges for Rechargeable Li Batteries. Chemistry of Materials, 22, 587-603. https://doi.org/10.1021/cm901452z

[6] Schmid, R. and Pillot, C. (2014) Introduction to Energy Storage with Market Analysis and Outlook. AIP Conference Proceedings, 1597, 3-13.

https://doi.org/10.1063/1.4878476

[7] Lee, J.I., Lee, E.H., Park, J.H., Park, S. and Lee, S.Y. (2014) Ultrahigh-Energy-Density Lithium-Ion Batteries Based on a High-Capacity Anode and a High-Voltage Cathode with an Electroconductive Nanoparticle Shell. Advanced Energy Materials, 4, 1301542. https://doi.org/10.1002/aenm.201301542

[8] Kalluri, S., Yoon, M., Jo, M., Park, S., Myeong, S., Kim, J., Dou, S.X., Guo, Z. and Cho, J. (2017) Surface Engineering Strategies of Layered $\mathrm{LiCoO}_{2}$ Cathode Material to Realize High-Energy and High-Voltage Li-Ion Cells. Advanced Energy Materials, 7, 1601507. https://doi.org/10.1002/aenm.201601507

[9] Chen, Z., Lu, Z. and Dahn, J.R. (2002) Staging phase transitions in $\mathrm{Li}_{\mathrm{x}} \mathrm{CoO}_{2}$. Journal of the Electrochemical Society, 149, A1604-A1609.

https://doi.org/10.1149/1.1519850

[10] Van der Ven, A., Aydinol, M.K., Ceder, G., Kresse, G. and Hafner, J. (1998) First-Principles Investigation of Phase Stability in $\mathrm{Li}_{\mathrm{x}} \mathrm{CoO}_{2}$. Physical Review B, 58, 2975. https://doi.org/10.1103/PhysRevB.58.2975

[11] Hausbrand, R., Cherkashinin, G., Ehrenberg, H., Gröting, M., Albe, K., Hess, C. and Jaegermann, W. (2015) Fundamental Degradation Mechanisms of Layered Oxide Li-Ion Battery Cathode Materials: Methodology, Insights and Novel Approaches. Materials Science and Engineering. B, 192, 3-25. https://doi.org/10.1016/j.mseb.2014.11.014

[12] Reimers, J.N. and Dahn, J.R. (1992) Electrochemical and in Situ X-Ray Diffraction 
Studies of Lithium Intercalation in $\mathrm{Li}_{\mathrm{x}} \mathrm{CoO}_{2}$. Journal of the Electrochemical Society, 139, 2091-2097. https://doi.org/10.1149/1.2221184

[13] Ohzuku, T. and Ueda, A. (1994) Solid-State Redox Reactions of $\mathrm{LiCoO}_{2}(\mathrm{R} 3 \mathrm{~m})$ for 4 Volt Secondary Lithium Cells. Journal of the Electrochemical Society, 141, 2972. https://doi.org/10.1149/1.2059267

[14] Ménétrier, M., Saadoune, I., Levasseur, S. and Delmas, C. (1999) The Insulator-Metal Transition upon Lithium Deintercalation from $\mathrm{LiCoO}_{2}$ : Electronic Properties and 7Li NMR Study. Journal of Materials Chemistry, 9, 1135-1140. https://doi.org/10.1039/a900016j

[15] Molenda, J., Stokłosa, A. and Bak, T. (1989) Modification in the Electronic Structure of Cobalt Bronze $\mathrm{Li}_{\mathrm{x}} \mathrm{CoO}_{2}$ and the Resulting Electrochemical Properties. Solid State Ionics, 36, 53-58. https://doi.org/10.1016/0167-2738(89)90058-1

[16] Van der Ven, A., Aydinol, M.K. and Ceder, G. (1998) First-Principles Evidence for Stage Ordering in $\mathrm{Li}_{\mathrm{x}} \mathrm{CoO}_{2}$. Journal of the Electrochemical Society, 145, 2149. https://doi.org/10.1149/1.1838610

[17] Amatucci, G.G., Tarascon, J.M. and Klein, L.C. (1996) $\mathrm{CoO}_{2}$, the End Member of the $\mathrm{Li}_{\mathrm{x}} \mathrm{CoO}_{2}$ Solid Solution. Journal of the Electrochemical Society, 143, 1114. https://doi.org/10.1149/1.1836594

[18] Radin, M.D., Hy, S., Sina, M., Fang, C., Liu, H., Vinckeviciute, J., Zhang, M., Whittingham, M.S., Meng, Y.S. and Van der Ven, A. (2017) Narrowing the Gap between Theoretical and Practical Capacities in Li-Ion Layered Oxide Cathode Materials. Advanced Energy Materials, 7, 1602888. https://doi.org/10.1002/aenm.201602888

[19] Kim, J., Fulmer, P. and Manthiram, A. (1999) Synthesis of $\mathrm{LiCoO}_{2}$ cathodes by an oxidation reaction in solution and their electrochemical properties. Materials research bulletin, 34, 571-579. https://doi.org/10.1016/S0025-5408(99)00049-5

[20] Yoshio, M., Tanaka, H., Tominaga, K. and Noguchi, H. (1992) Synthesis of $\mathrm{LiCoO}_{2}$ from Cobalt Organic Acid Complexes and Its Electrode Behaviour in a Lithium Secondary Battery. Journal of Power Sources, 40, 347-353. https://doi.org/10.1016/0378-7753(92)80023-5

[21] Oh, I.-H., Hong, S.-A. and Sun, Y.-K. (1997) Low-Temperature Preparation of Ultrafine $\mathrm{LiCoO}_{2}$ Powders by the Sol-Gel Method. Journal of Materials Science, 32, 3177-3182. https://doi.org/10.1023/A:1018650717723

[22] Peng, Z.S., Wan, C.R. and Jiang, C.Y. (1998) Synthesis by Sol-Gel Process and Characterization of $\mathrm{LiCoO}_{2}$ Cathode Materials. Journal of Power Sources, 72, 215-220. https://doi.org/10.1016/S0378-7753(97)02689-X

[23] Burukhin, A., Brylev, O., Hany, P. and Churagulov, B.R. (2002) Hydrothermal Synthesis of $\mathrm{LiCoO}_{2}$ for Lithium Rechargeable Batteries. Solid State Ionics, 151, 259-263. https://doi.org/10.1016/S0167-2738(02)00721-X

[24] Lu, C.H. and Wang, H.C. (2003) Synthesis of Nano-Sized $\mathrm{LiNi}_{0.8} \mathrm{Co}_{0.2} \mathrm{O}_{2}$ via a Reverse Microemulsion Route. Journal of Materials Chemistry, 13, 428-431. https://doi.org/10.1039/b204394g

[25] Chen, C.H., Kelder, E.M. and Schoonman, J. (1996) Unique Porous $\mathrm{LiCoO}_{2}$ Thin Layers Prepared by Electrostatic Spray Deposition. Journal of Materials Science, 31, 5437-5442. https://doi.org/10.1007/BF01159314

[26] Kumta, P.N., Gallet, D., Waghray, A., Blomgren, G.E. and Setter, M.P. (1998) Synthesis of $\mathrm{LiCoO}_{2}$ Powders for Lithium-Ion Batteries from Precursors Derived by Rotary Evaporation. Journal of Power Sources, 72, 91-98. https://doi.org/10.1016/S0378-7753(97)02680-3

[27] Xie, J., Zhao, J., Liu, Y., Wang, H., Liu, C., Wu, T., Hsu, P.-C., Lin, D., Jin, Y. and 
Cui, Y. (2017) Engineering the Surface of $\mathrm{LiCoO}_{2}$ Electrodes Using Atomic Layer Deposition for Stable High-Voltage Lithium Ion Batteries. Nano Research, 10, 3754-3764. https://doi.org/10.1007/s12274-017-1588-1

[28] Julien, C. (2000) Local Cationic Environment in Lithium Nickel-Cobalt Oxides Used as Cathode Materials for Lithium Batteries. Solid State Ionics, 136, 887-896. https://doi.org/10.1016/S0167-2738(00)00503-8

[29] Julien, C. (2003) Local Structure and Electrochemistry of Lithium Cobalt Oxides and Their Doped Compounds. Solid State Ionics, 157, 57-71.

https://doi.org/10.1016/S0167-2738(02)00190-X

[30] Ceder, G. and Aydinol, M.K. (1998) The Electrochemical Stability of Lithium-Metal Oxides against Metal Reduction. Solid State Ionics, 109, 151-157. https://doi.org/10.1016/S0167-2738(98)00090-3

[31] Choi, S. and Manthiram, A. (2002) Chemical Synthesis and Properties of Spinel $\mathrm{Li}_{1-}$ ${ }_{x} \mathrm{Co}_{2} \mathrm{O}_{4-\delta}$. Journal of Solid State Chemistry, 164, 332-338. https://doi.org/10.1006/jssc.2001.9480

[32] Kalyani, P., Kalaiselvi, N. and Muniyandi, N. (2002) A New Solution Combustion Route to Synthesize $\mathrm{LiCoO}_{2}$ and $\mathrm{LiMn}_{2} \mathrm{O}_{4}$. Journal of Power Sources, 111, 232-238. https://doi.org/10.1016/S0378-7753(02)00307-5

[33] Huang, W. and Frech, R. (1996) Vibrational Spectroscopic and Electrochemical Studies of the Low and High Temperature Phases of $\mathrm{LiCo}_{1-\mathrm{x}} \mathrm{M}_{\mathrm{x}} \mathrm{O}_{2}(\mathrm{M}=\mathrm{Ni}$ or Ti). Solid State Ionics, 88-89, 395-400. https://doi.org/10.1016/0167-2738(96)00158-0

[34] Burba, C.M., Shaju, K.M., Bruce, P.G. and Frech, R. (2009) Infrared and Raman Spectroscopy of Nanostructured LT-LiCoO ${ }_{2}$ Cathodes for Li-Ion Rechargeable Batteries. Vibrational Spectroscopy, 51, 248-250. https://doi.org/10.1016/j.vibspec.2009.06.002

[35] Islam, K.H., Zuki, A.B.Z., Ali, M.E., Hussein, B., Zobir, M., Noordin, M.M., Loqman, M.Y., Wahid, H., Hakim, M.A., Hamid, A. and Bee, S. (2012) Facile Synthesis of Calcium Carbonate Nanoparticles from Cockle Shells. Journal of Nanomaterials, 2012. https://doi.org/10.1155/2012/534010

[36] Ghosh, P., Mahanty, S., Raja, M.W., Basu, R.N. and Maiti, H.S. (2007) Structure and Optical Absorption of Combustion-Synthesized Nanocrystalline $\mathrm{LiCoO}_{2}$. Journal of Materials Research, 22, 1162-1167. https://doi.org/10.1557/jmr.2007.0157

[37] JCPDS Reference Code. 01-078-3137.

[38] Gao, W., Zhang, X., Zheng, X., Lin, X., Cao, H., Zhang, Y. and Sun, Z. (2017) Lithium Carbonate Recovery from Cathode Scrap of Spent Lithium-Ion Battery: A Closed-Loop Process. Environmental Science \& Technology, 51, 1662-1669. https://doi.org/10.1021/acs.est.6b03320

[39] Prabaharan, D.D.M., Sadaiyandi, K., Mahendran, M. and Sagadevan, S. (2017) Precipitation Method and Characterization of Cobalt Oxide Nanoparticles. Applied Physics A, 23, Article No.: 264. https://doi.org/10.1007/s00339-017-0786-8

[40] Madhavi, S., Rao, G.S., Chowdari, B.V.R. and Li, S.F.Y. (2002) Effect of Cr Dopant on the Cathodic Behavior of $\mathrm{LiCoO}_{2}$. Electrochimicaacta, 48, 219-226. https://doi.org/10.1016/S0013-4686(02)00594-7

[41] Zhong, Y.D., Zhao, X.B., Cao, G.S., Tu, J.P. and Zhu, T.J. (2006) Characterization of Particulate Sol-Gel Synthesis of $\mathrm{LiNi}_{0.8} \mathrm{Co}_{0.2} \mathrm{O}_{2}$ via Maleic Acid Assistance with Different Solvents. Journal of Alloys and Compounds, 420, 298-305. https://doi.org/10.1016/j.jallcom.2005.10.052

[42] Cullity, BD. and Stock SR. (2001) Elements of X-Ray Diffraction. 3rd Edition, Prentice Hall, Upper Saddle River. 
[43] Akimoto, J., Gotoh, Y. andOosawa, Y. (1998) Synthesis and Structure Refinement of $\mathrm{LiCoO}_{2}$ Single Crystals. Journal of Solid State Chemistry, 141, 298-302. https://doi.org/10.1006/jssc.1998.7966

[44] Mehl, M.J., Hicks, D., Toher, C., Levy, O., Hanson, R.M., Hart, G. and Curtarolo, S. (2017) The AFLOW Library of Crystallographic Prototypes: Part 1. Computational Materials Science, 136, S1-S828. https://doi.org/10.1016/j.commatsci.2017.01.017

[45] Konstantinov, K., Wang, G.X., Yao, J., Liu, H.K. and Dou, S.X. (2003) Stoichiometry-Controlled High-Performance $\mathrm{LiCoO}_{2}$ Electrode Materials Prepared by a Spray Solution Technique. Journal of Power Sources, 119,195-200. https://doi.org/10.1016/S0378-7753(03)00178-2

[46] Graetz, J., Hightower, A., Ahn, C.C., Yazami, R., Rez, P. and Fultz, B. (2002) Electronic Structure of Chemically-Delithiated $\mathrm{LiCoO}_{2}$ Studied by Electron Energy-Loss Spectrometry. The Journal of Physical Chemistry, 106, 1286-1289.

https://doi.org/10.1021/jp0133283

[47] Van Elp, J., Wieland, J.L., Eskes, H., Kuiper, P., Sawatzky, G.A., De Groot, F.M.F. and Turner, T.S. (1991) Electronic Structure of CoO, Li-Doped CoO, and $\mathrm{LiCoO}_{2}$. Physical Review B, 44, 6090. https://doi.org/10.1103/PhysRevB.44.6090

[48] De Groot, F.M.F., Abbate, M., Van Elp, J., Sawatzky, G.A., Ma, Y.J., Chen, C.T. and Sette, F. (1993) Oxygen 1s and Cobalt 2p X-Ray Absorption of Cobalt Oxides. Journal of Physics. Condensed Matter, 5, 2277. https://doi.org/10.1088/0953-8984/5/14/023

[49] Kushida, K. and Kuriyama, K. (2002) Narrowing of the Co-3d Band Related to the Order-Disorder Phase Transition in $\mathrm{LiCoO}_{2}$. Solid State Communications, 123, 349-352. https://doi.org/10.1016/S0038-1098(02)00325-3

[50] Czyżyk, M.T., Potze, R. and Sawatzky, G.A. (1992) Band-Theory Description of High-Energy Spectroscopy and the Electronic Structure of $\mathrm{LiCoO}_{2}$. Physical Review $B, 46,3729$. https://doi.org/10.1103/PhysRevB.46.3729

[51] Kashyout, A.B., Soliman, M., El Gamal, M. and Fathy, M. (2005) Preparation and Characterization of Nano Particles ZnO Films for Dye-Sensitized Solar Cells. Materials Chemistry and Physics, 90, 230-233. https://doi.org/10.1016/j.matchemphys.2004.11.031 